\title{
A ABORDAGEM INTERACIONISTA DA MULTIMODALIDADE TEXTUAL E O ENSINO CRÍTICO DE LEITURA
}

\author{
Fernanda Dias De Los Rios Mendonça ${ }^{1}$
}

\section{RESUMO}

Considerando a emergência dos novos letramentos, sobretudo no que concerne ao aspecto multimodal de textos pertencentes a gêneros discursivos recorrentes nas esferas públicas, através dos quais interagem diferentes sujeitos sociais do atual mundo globalizado, impõem-se-nos as urgentes tarefas de refletir sobre o estatuto do texto nas práticas sociais da vida contemporânea e de reconsiderar os processos de ensino-aprendizagem de leitura a que são submetidos os alunos - sujeitos em formação, leitores críticos em potencial. Desta feita, objetivamos, neste artigo, apresentar a leitura de um texto multimodal pertencente ao gênero capa de revista, nos termos em que pressupomos deva a leitura ser realizada no âmbito escolar. Para tanto, ancoramo-nos nas perspectivas interacional de linguagem e crítica de leitura, respectivamente subsidiadas em Bakhtin e Freire e de alguma forma contempladas ambas nos ideários subjacentes aos Parâmetros Curriculares Nacionais de Língua Portuguesa. Ressaltamos que a leitura aqui realizada apresenta-se mais adequada para o segmento Ensino Médio, em função do tema e dos conhecimentos levantados para sua apreensão, não pretendendo, no entanto, servir de modelo ou proposta metodológica, o que iria de encontro às perspectivas que nortearam esse trabalho.

Palavras-Chave: Multimodalidade. Perspectiva sociointeracionista. Leitura crítica. Ensino.

\section{INTRODUÇÃO}

As práticas e eventos de letramento, incipientes no atual mundo globalizado, impõe-nos a necessidade de redefinição do conceito de texto, impelindo-nos a considerar a textualidade numa perspectiva mais ampla, constituída por elementos de naturezas ontologicamente distintas, que se entrecruzam para a construção de um sentido cujo fim é concretizar, na materialidade do texto, um projeto de dizer. Tal redefinição, por conseguinte, exige uma ampliação do conceito de língua/linguagem. Para tanto, ancoramo-nos sob a concepção de linguagem interacionista bakhtiniana e adotamos a perspectiva crítica de leitura freireana.

Esclarecemos que nosso foco de interesse neste artigo está no processo de ensino-aprendizagem da leitura como componente fundamental da disciplina Língua 
Portuguesa, particularmente de textos multimodais, em função de essa multimodalidade ser ainda ineficientemente trabalhada no contexto escolar e tratada de modo tangencial no corpus teórico da Linguística Textual, conforme apontam Bentes e Leite (2008, p. 21). Para tanto, elucidamos, na seção seguinte, a abordagem de leitura e de linguagem que defendemos deva ser contemplada no Ensino de Língua Materna, o papel central do texto nas diretrizes apresentadas pelo Parâmetro Curricular Nacional de Língua Portuguesa (doravante PCN), as especificidades dos gêneros multimodais e os conceitos de coesão e coerência da Linguística Textual, apresentando, posteriormente, a leitura do texto multimodal subsidiada pelos pressupostos apresentados.

\section{LEITURA CRÍTICA E INTERACIONISMO: PERSPECTIVAS DE ENSINO}

A proposta pedagógica defendida por Paulo Freire para o ensino em geral e para o ensino de leitura particularmente destacado neste artigo é fundada sobretudo em um posicionamento fortemente político, acarretando como imprescindíveis a conscientização e o posicionamento axiológico do educador diante de sua práxis pedagógica. Nessa perspectiva de comprometimento político do processo educativo, a leitura possui papel central, pois é por meio dela, que se dá o processo de apreensão, compreensão e reflexão crítica do educando acerca de seu papel social e das relações de poder que mantém a estrutura da sociedade a que pertence, viabilizando seu posicionamento enquanto cidadão atuante e interventor na esfera social e política vigente.

Ao retomar o seu processo particular de constituição como leitor da palavra no trabalho intitulado "A importância do ato de ler", Freire (1982) revela como pontos fundamentais da ação pedagógica em relação à leitura a consideração do mundo prévio ao escolar do qual os sujeitos/educandos fazem parte e que, portanto, influenciam diretamente na constituição da sua formação leitora, e a valorização da participação ativa desses sujeitos na constituição de seus conhecimentos. Tais considerações são, segundo o autor, determinantes para o desenvolvimento de uma ação pedagógica que viabilize o posicionamento autônomo do educando em diversos contextos sociais.

A educação assim constituída estará, como deve, respondendo e interagindo com as questões sociais mais imediatas, através da relação dialógica que 
estabelece, a partir da formação dos sujeitos, com as demais instâncias e esferas sociais, substituindo a neutralidade e isolamento com que muitas vezes é intencionalmente levada a ser considerada pela assunção do papel político que deve exercer em toda sociedade.

Ao referir-se à leitura codificada aprendida na escola como a leitura da palavra, Freire opõe-na à leitura do mundo e propõe que a constituição do leitor da palavra, cuja apreensão se dá no âmbito escolar, corresponda necessariamente à constituição do leitor da palavra mundo. Em outros termos, o processo de formação do aluno-leitor deve estar focado na sua formação enquanto leitor-sujeito, visando despertar sua autonomia, sua consciência crítica, levando-o a compreender as ideologias subjacentes aos textos veiculados nas diferentes esferas da sociedade, sem deixar de considerar, no entanto, seus conhecimentos prévios e sua posição axiológica, influenciada pelo lugar que ocupa no escopo social.

A leitura, assim, não pode limitar-se ao entendimento superficial das palavras e sentenças que compõem o corpo textual, que não alcança as entrelinhas subjacentes ao plano literal das estruturas linguísticas. Ao contrário, a leitura projetada pelo autor pressupõe a transcendência do plano superficial da expressão, pelo acionamento de sentidos autorizados por seus elementos constituintes, relacionados ao universo contextual que o sobrepuja.

Ler para além da palavra implica em sair dos cotextos aparentemente autônomos dos textos e percebê-los sempre como unidades de um todo maior, os contextos imediatos e mediatos nos quais, dos quais e para os quais são constituídos; implica em relacioná-los às esferas ideológicas a que servem, às funções sociais que exercem. Apreender tais relações, consequentemente, implica em compreender as regras vigentes nas esferas que compõem os diversos subsistemas que mantêm em funcionamento a estrutura social, que direcionam os textos que circulam por ela, as relações estabelecidas entre os sujeitos que a constituem, os limites estabelecidos entre o que se deve, pode ou não dizer.

Conforme observou Britto (2007, p. 62-63) "o que ensina Paulo Freire com essa reflexão é que a educação não se dá em substrato, de forma independente dos modos concretos de vida coletiva”, antes, um ensino que se proponha crítico deve necessariamente considerar a realidade dos demais âmbitos sociais para além dos muros da escola e das paredes de suas salas de aula. Essa visão de ensino defendida por Freire vai ao encontro da perspectiva interacionista de linguagem 
centrada nas relações intersubjetivas que se estabelecem dialogicamente entre os sujeitos sociais e ancorada em Bakhtin.

O ensino de leitura pressupõe um conceito de texto e este, por sua vez, pressupõe um conceito de língua/linguagem. A concepção de texto adotada aqui corresponde a uma noção alargada em relação à noção mais imanente dos estudos textuais e está vinculada à perspectiva de língua/linguagem ancorada nos pressupostos teórico-filosóficos do Círculo de Bakhtin.

Para Bakhtin e seus pares, a língua é vista na sua condição de discurso, como interação social, através da qual os sujeitos se constituem mutuamente na relação dialógica que estabelecem, por meio da qual praticam ações e agem sobre seus interlocutores e vice-versa. Portanto, a leitura de textos/discursos deve necessariamente considerar as condições de sua produção e os interlocutores envolvidos no processo interacional em que são produzidos.

Em outras palavras, o processo de leitura no âmbito da perspectiva interacionista deve partir do entorno social e suas implicações, do enunciador, sua posição axiológica e intenção discursiva, a esfera social e ideológica ao qual está vinculado, o suporte em que é enunciado. Contudo, não pode prescindir do acionamento dos signos linguísticos e não linguísticos que constituem a estrutura que o materializa, isto é, o processo de leitura se dá pela associação dessas duas contrapartes para a construção do sentido subjacente ao enunciado textual. Isso porque

O discurso, quando produzido, manifesta-se linguisticamente por meio de textos. O produto da atividade discursiva oral ou escrita que forma um todo significativo, qualquer que seja sua extensão, é o texto, uma sequência verbal constituída por um conjunto de relações que se estabelecem a partir da coesão e da coerência. (BRASIL, 1998, p. 21)

Essa relação entre texto e discurso, justifica o papel central do primeiro na proposta de ensino e aprendizagem veiculada pelos PCNs, segundo a qual todo conteúdo deve ser organizado em torno do eixo USO - REFLEXÃO - USO, já que postula como objetivo final a promoção do desenvolvimento das competências linguística e discursiva e estilística do aluno, a fim de que esse se torne apto a interagir em diversas situações sociais. A leitura, inserida no eixo do uso da língua, corresponde a uma das formas de interação entre diferentes sujeitos de participação, portanto, em práticas sociais e tanto ela como as demais possibilidades de realização da linguagem se dão por meio da materialidade textual. 
Não é difícil perceber a estreita relação entre a proposta crítica de leitura freireana, a perspectiva interacionista bakhtiniana e a proposta de ensinoaprendizagem dos PCNs. Embora não haja nenhuma menção nos PCNs à contribuição teórica desses dois autores para a sua elaboração, além das referências ao final do documento, ficam nítidas no discurso subjacente a esse a perspectiva de linguagem, ancorada na visão interacional e dialógica de Bakhtin, e a preocupação política e social da educação, subsidiada pela proposta pedagógica de Paulo Freire.

De fato, uma teoria coaduna com a outra, fomentando, juntas, "um projeto educativo comprometido com a democratização social e cultural (que) atribui à escola a função e a responsabilidade de contribuir para garantir a todos os alunos o acesso aos saberes linguísticos necessários para o exercício da cidadania". (BRASIL, 1988, p.19). Para tanto, deve levar em conta todos os usos da linguagem presentes na sociedade, de modo especial os pertencentes aos domínios públicos, considerando o estabelecimento das novas relações que vão surgindo com os avanços das tecnologias emergentes no contexto globalizante em que as sociedades se encontram, bem como a própria constituição estrutural desses usos, viabilizada pelo surgimento e avanço de recursos cada vez mais sofisticados, como é o caso daqueles utilizados em textos multimodais.

O conceito de multimodalidade tomado neste artigo consiste na noção de que a constituição da tessitura de um texto multimodal se faz pelo entrelaçamento entre signos verbais e elementos semióticos extralinguísticos, resultando na produção do sentido global do enunciado. Essa relação que se dá entre elementos de naturezas ontológicas distintas, não ocorre aleatoriamente, mas resulta de um processo de elaboração cujo ponto de partida é o próprio projeto de dizer do sujeito que a concretiza no corpo textual.

Postulamos que quatro implicações ao menos emanam de textos constituídos de forma multimodal: (a) nenhum elemento e/ou recurso presente, por mais sutil que possa parecer, pode ser dispensado para a compreensão do texto; (b) a composição da coesão e da coerência textuais se dão pelo entrelaçamento de componentes verbais e não-verbais e (c) o processo de leitura não se dá linearmente. Levando em conta as especificidades elencadas e a abordagem interacionista tomada como âncora para o ensino veiculado nos documentos oficiais, temos que qualquer trabalho com leitura de textos multimodais deve considerar cada um dos fatores 
mencionados acima em seu processo. Para tanto, o conhecimento de dois pressupostos básicos da linguística textual torna-se fundamental para o auxílio do mesmo.

Situamo-nos, dentre as abordagens dos estudos textuais, à de cunho sociocognitiva e interacionista defendida por linguistas como Koch e Travaglia (2001) dos quais tomamos os conceitos da Linguística Textual, considerando, para fins de análise textual, os princípios de coesão e coerência, dos quais decorrem os demais. Como coesão, compreendemos todo movimento remissivo ou sequencial que tanto garante a manutenção da temática textual, como contribui para sua progressão, através dos processos de introdução e referenciação a objetos instituídos no discurso; como coerência, consideramos todos os fatores que colaboram para o sentido global do texto. Ambos, coesão e coerência, juntos, garantem a constituição da tessitura textual, entendida como o que caracteriza o texto como tal, dando-lhe esse estatuto.

Vale ressaltar que nossa proposta é apresentar uma atividade de leitura em consonância com as perspectivas já mencionadas, o que implica no fato de que os pressupostos da Linguística Textual funcionam não como fim, mas como auxiliadores nesse processo, cooperando, por meio da prática mediadora docente, com o desenvolvimento nos alunos das competências necessárias para a realização da leitura aqui pressuposta, conforme esperamos deixar claro com o exemplo da leitura realizada abaixo.

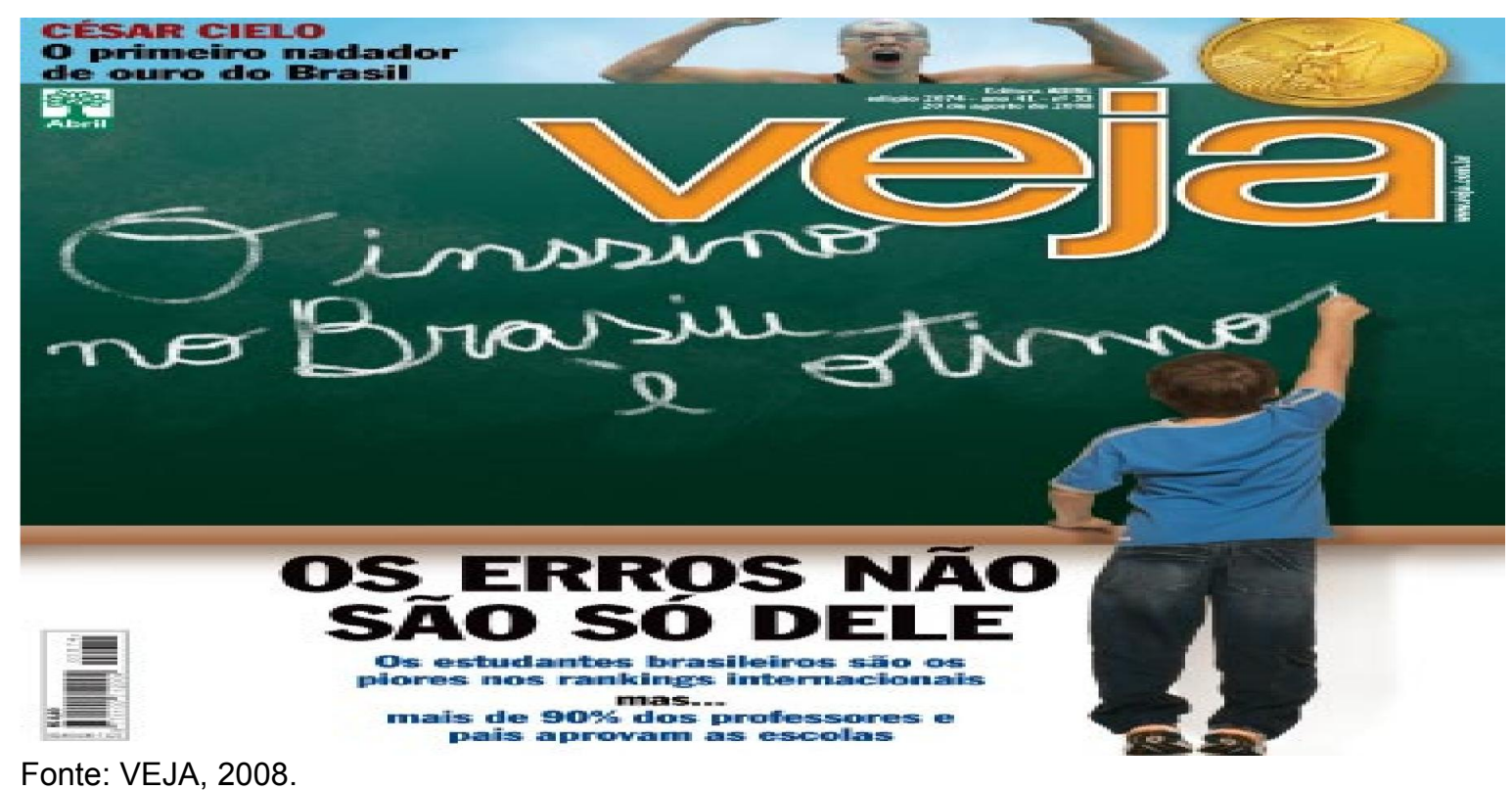


Uma abordagem de leitura que se pretende interacionista e crítica deve partir sempre das seguintes perguntas: quem é o autor? A quem se dirige? Com que intenção? Ou qual é seu projeto de dizer? E em que esfera sócio-discursiva o texto se inscreve como discurso? As questões pontuadas devem direcionar o processo de leitura do texto. Antes, porém, faz-se necessário identificar o gênero a que pertence.

Embora não tenhamos reservado um espaço específico neste artigo para a noção de gênero discursivo, primeiro por pressupor que já seja consensual sua abordagem em qualquer atividade de uso da língua e, segundo, pelo espaço delimitado para este trabalho, partimos dele para iniciar a leitura da capa de revista, já que ele revela dados fundamentais para sua compreensão, desde a estrutura composicional, passando pelo uso da linguagem, até a esfera social a qual pertence e, portanto, à sua funcionalidade.

Mesmo um olhar desatento permite ao leitor identificar o texto apresentado como pertencendo ao gênero discursivo capa de revista. Alguns fatores nos permitem chegar a tal conclusão, como o modo de disposição dos elementos semióticos e linguísticos. Incluem-se, entre os elementos linguísticos, aqueles que figuram como fatores contextualizadores que nos dão informações sobre a revista (Editora Abril, o número da revista e a data de sua edição, 20 de agosto de 2008), permitindo-nos dar respostas a algumas questões pontuadas acima. Voltemos a elas.

A pergunta quem escreve, nos remete à questão da autoria. Sabemos que há um sujeito que materializa o texto da capa, mas ao autor corresponde àquele que assina, assumindo a responsabilidade pelo discurso nele veiculado, no caso do texto que analisamos, trata-se de uma responsabilidade institucional, assinada por Veja. Logo, Veja é não apenas o nome da revista, mas o responsável autoral pelos textos assinados por ela.

A identificação do autor, do responsável, nos leva à identificação dos interlocutores possíveis, portanto, devemos definir, caracterizar Veja, enquanto autoria institucional. Veja é uma revista de tiragem semanal, destinada aos leitores da classe média da sociedade brasileira, portanto, os temas e matérias que veicula são dirigidos por um projeto de dizer que é sempre direcionado aos interesses desse grupo social e atravessados pela posição axiológica que o representa e que a revista assume enquanto produtora de discurso. 
A capa focaliza um referente discursivo representado pelo menino que aparece de costas, escrevendo no quadro negro a giz, representando metonimicamente estudantes brasileiros, sendo retomado coesivamente pelo pronome "ele" da sentença "Os erros não são só dele" . O estabelecimento dessa referenciação viabiliza a continuidade do enunciado, fazendo menção a um novo referente discursivo "erros", que, por sua vez, liga-se de forma remissiva aos "erros" de ortografia cometidos pelo menino, mas também remete aos "erros" de $90 \%$ de professores e pais que aprovam as escolas, embora os estudantes brasileiros sejam os piores nos rankings internacionais.

Essa relação é enfatizada com o uso do advérbio "mas" que aparece destacado pelos recursos semióticos da posição e da cor, contrastando duas ideias: de um lado, o péssimo nível de ensino dos estudantes brasileiros e de outro, o dado em percentual da aprovação de professores e pais em relação às escolas, focalizando a disparidade de tais informações, recurso que provoca e instiga a leitura da matéria para esclarecimento das mesmas, intrigando os pais, leitores da revista, que, como mencionado na capa, supõem estejam pagando um ensino "de qualidade" aos filhos.

A vestimenta com que o menino da capa aparece representado revela mais uma vez a intenção diretiva do texto, pois representa jovens da classe média, não de alunos de escolas públicas, e tudo na imagem, desde a coloração até a organização direcionam a leitura para essa percepção.

Compondo a capa, há uma imagem não central que apresenta um referente discursivo na imagem de um nadador comemorando vitória que é retomado duas vezes, uma nomeando-o, "César Cielo", e outra, atribuindo-lhe uma informação adicional, "primeiro nadador de ouro do Brasil". A locução "de ouro" funciona ambiguamente, atribuindo por um lado uma adjetivação positiva ao nadador, à semelhança de ótimo nadador, por outro, remetendo à medalha que ele ganhou em competição internacional e que está ilustrada ao lado direito da imagem.

Temos então um contrassenso composto pela associação das duas imagens: um ensino de péssima qualidade, o pior no ranking internacional e uma medalha de ouro no âmbito esportivo, também internacional. Essa "combinação" pressupõe a imagem do Brasil visto pelo outro, de fora e, portanto, inserido num contexto global, mais amplo. 
Lembremos da primeira implicação dos textos multimodais de que nada deve ser desconsiderado em sua leitura e ficará evidente que, embora as imagens, aparentemente, não tenham nenhuma relação, foram selecionadas para concretizar um projeto enunciativo. Assim como cada recurso utilizado para a materialização deste, como a posição das matérias destacadas na capa, que indica não apenas a prevalência de importância da matéria cuja imagem ocupa o espaço central da capa, mas também a posição superior do nadador diante do aluno. Fica clara a intenção da Veja de chamar atenção, a fim de tornar seu produto vendável, intenção propulsora de seus projetos enunciativos, diretamente relacionados à esfera enunciativa que representa.

Uma leitura superficial identificaria o texto como sendo uma capa da revista Veja, que trata das péssimas condições de ensino no Brasil, situação que, segundo ela, passa despercebido por pais e professores. No entanto, conforme as diretrizes teóricas que subsidiam esse trabalho, essa leitura corresponderia a uma simples decodificação, já que não leva o leitor a uma compreensão abrangente e situada do texto, não compromete o autor nem questiona sua intenção discursiva, tão pouco relaciona o texto ao contexto social, cultural e histórico em que se encontra inserido, sendo, portanto, incapaz de retirar dele o pressuposto ideológico que delineia sua elaboração discursiva e que justifica a composição da materialidade textual.

O gênero capa de revista tem como especificidade o fato de servir de chamada para outro texto, de maior extensão e no qual o tema abordado aparece mais detalhadamente tratado, como um complemento, portanto, da capa que o introduz. Além disso, a capa e a matéria de que faz menção servem de estratégia de marketing para a venda da revista e para a veiculação das demais matérias abordadas na mesma, exercendo importante função institucional que deve ser considerada na sua leitura.

A leitura crítica que propomos aqui consiste em identificar a razão da matéria abordada, a intencionalidade em sua veiculação, a sua situacionalidade, ou filtragem através da qual enuncia fatos da realidade, a focalização, ou o que é selecionado e como é abordado, e a relação dessa enunciação em relação ao contexto sociopolítico e histórico mediato e imediato.

O autor (Veja) direciona um discurso sobre a qualidade de ensino e nisso revela o conceito de ensino que considera como desejável, o ensino tradicional, baseado na decodificação. Esse posicionamento pode ser percebido diante do 
objeto a que faz alusão como "erros", os desvios ortográficos, e que no texto consiste na representação da má qualidade de ensino no Brasil, não havendo menção à formação do sujeito social, mas de um indivíduo que deve adquirir conhecimentos prontos, predeterminados que o instrumentalizarão para o mercado de trabalho. Trata-se da educação bancária criticada por Freire. A forma como a questão do ensino é tratada leva à suposição de que os responsáveis por essa educação são os pais e os professores, que se mostram satisfeitos com a mesma e em nenhum momento essa questão é focalizada de forma a considerar as implicações políticas, econômicas e sociais que interferem diretamente nelas.

Para que possamos compreender o que se defende no discurso subjacente ao texto da capa, isto é, sua intencionalidade, devemos situá-lo em seu contexto sócio-histórico imediato, a sociedade brasileira do século XXI e relacioná-lo à esfera escolar e ao ensino que se tem defendido e procurado colocar em prática nas escolas públicas e particulares. Um ensino interacionista que visa viabilizar o alçamento do aluno enquanto cidadão e garantir sua inserção crítica e ativa nas diferentes esferas sociais.

Diante dessas considerações, percebemos que a preocupação da revista não é com as causas, tampouco com as implicações dos problemas educacionais para a vida dos sujeitos da classe menos favorecida economicamente, mas todo o seu discurso é elaborado na intenção de fazer apologia ao consumo, aos valores impostos pelo sistema capitalista e globalizante que aliena e deturpa as necessidades e determina as ações humanas. E nesse sentido, o ensino que se deseja é o de aquisição de conhecimentos pré-estabelecidos, que devem ser decodificados e assimilados passivamente pelos alunos, a fim de que esses se constituam eficientes produtores para a demanda do mercado de trabalho. O ensino medido por coeficiente de rendimento e de acertos de respostas decoradas.

Tal leitura demanda um conhecimento prévio do leitor, um conhecimento de mundo que é tratado em seu discurso e que é (ou se pressupõe) ser compartilhado com o autor do texto. No entanto, conseguimos confirmar com maior clareza o projeto discursivo veiculado nesse, se estendermos nossa leitura para a matéria que o complementa, o que também é importante tratar em sala de aula, haja vista a peculiaridade do gênero capa de revista constituir-se como parte de uma unidade que se sobrepõe a ele e, de certa forma, o determina. 
Assim, intencionalmente estendemos a leitura no escopo deste trabalho, assim como selecionamos esse texto de 2008 em detrimento de outros mais recentes, justificando nossa opção pelo tratamento dado ao tema que, de forma marcadamente oposta, defendemos nas linhas deste artigo. As demais páginas da matéria que dão continuidade à capa, no interior da revista, sem preocupações em camuflar sua real intenção, consistem num amontoado de frases que, com o intuito de defender um ensino sistemático e bancário, denigrem figuras de substancial representação histórica, como Paulo Freire e Karl Marx, para citar apenas dois, e postulam como a causa do insucesso escolar a imposição, por parte de professores e instituições de ensino, de ideologias de cunho esquerdista que vão contra as reais necessidades do mercado globalizado, num deflagrado discurso ideológico direitista, deturpando, inclusive, as propostas desses pensadores.

Deixamos registrado que nossa intenção no presente trabalho não é a de propor uma leitura dogmática, mas apontar a ideologia e a intenção política que delineia o discurso do texto analisado, conforme o sentido de leitura proposta pelas abordagens teóricas que ancoram esse trabalho, ainda que não se possa negar que toda leitura é, no sentido bakhtiniano, ideologicamente orientada.

Embora os textos veiculados na revista sejam outros textos, consideramos relevante mencioná-los no processo de leitura da capa, dado o fato de constituírem sua extensão e a possibilidade de viabilizar um olhar mais amplo e crítico sobre a mesma, a partir da intertextualidade entre eles. No caso da leitura realizada aqui, tais textos foram imprescindíveis para mostrar que a leitura que realizamos da capa é autorizada, legitimada e confirmada pelos textos que remetem a ela.

Considerando o contexto de sua produção e partindo do pressuposto de que toda escolha corresponde a uma posição axiológica, podemos ler a seleção da capa, matéria central da revista, e, portanto, tomada como sendo a de maior importância, um recurso para minimizar a repercussão e deixar o leitor à margem de situações de cunho político, social e econômico no âmbito nacional (imediato) e internacional (mediato) importantes para esses cenários e que deveriam ser focalizadas para o leitor, como na época a questão da exploração do petróleo no Brasil, perifericamente mencionada no interior da mesma revista, apenas para citar um caso. Tal fato nos leva a inferir, e isso é imprescindível para uma leitura crítica, o poder que a esfera da comunicação, representada aqui pela Veja, representa, no sentido de caber a ela 
não apenas a seleção das informações a serem levadas aos sujeitos sociais mas, sobretudo, o poder de manipulação dessas informações.

Poderíamos nos estender mais na leitura do texto, mas o exíguo espaço destinado ao artigo nos coloca o encargo de finalizar a análise, sem maiores adentramentos. Desta forma, concluímos prefigurando a Capa da revista como um discurso que coaduna com os sistemas político e econômico hegemônicos no Brasil, que se utiliza do poder de controle de informação que possui para trabalhar discursivamente em prol da ideologização dos leitores a que se destina, a fim de que, dominados por essa imposição ideológica disfarçada nos moldes atrativos da Capa, ajam sob sua força e transformem-se em seus agentes propagadores, perpetuando as esferas econômicas e políticas que através do discurso veiculado por ela se mantém no controle social.

\section{CONSIDERAÇÕES FINAIS}

Nossa intenção neste artigo foi apresentar um exemplo do que chamamos de leitura crítica, conscientes de que não há, nem pode haver um modelo pronto de leitura a ser seguido no curso do processo de ensino-aprendizagem de língua portuguesa. Subsidiados pelos pressupostos que nos guiaram na elaboração deste trabalho, entendemos e esperamos ter colaborado para o entendimento do leitor que à formação leitora de um aluno é imprescindível a formação leitora do professor, que deve ter clareza de sua função social e mostrar ao aluno que todo texto é constituído por sujeitos que respondem valorativamente a realidades extratextuais.

Uma preocupação fundante para a escrita deste artigo foi mostrar que a leitura no âmbito escolar não precisa dar-se "escolarizadamente", no sentido de seguir modelos ou tópicos pré-fixados para sua realização. Tampouco pode ater-se à prática de identificação de características padronizadas de gêneros discursivos. Ao contrário, esses servem para orientar a leitura enquanto processo de interação entre sujeitos situados social, temporal e historicamente e, portanto, favorecer a compreensão da função social que o texto exerce.

Outra preocupação, que ancorou a seleção do texto apresentado, foi o espaço periférico da multimodalidade textual nas aulas de leitura e sua noção ainda restritamente relacionada apenas a textos veiculados no ambiente virtual, razão pela qual optamos pela capa de revista, a fim de mostrar a impossibilidade de ignorar o 
aspecto multimodal atualmente presente na grande maioria dos textos que circulam socialmente em suportes impressos e que é imprescindível para sua contextualização e compreensão, o que nos leva à ressignificação do conceito de texto ainda entendido por muitos como constituído exclusivamente por signos linguísticos.

Esperamos ter deixado claro também a relação não dicotômica entre pressupostos da Linguística Textual e os de cunho Discursivo Interacionista, mas apresentá-los, ambos, como inerentes à constituição da linguagem, seja no âmbito da materialidade textual, seja no âmbito da concretização discursiva, o que pressupõe que se complementam e são, portanto, imprescindíveis a uma leitura afinada à proposta deste trabalho, o que pressupõe que a concepção de texto não pode permanecer restrita ao domínio da matéria textual, da mesma forma que, como dito no parágrafo anterior, não se pode restringir seus elementos constitutivos ao âmbito linguístico.

Finalmente, concluímos, propositadamente sem fechar a análise do texto, ancorados na perspectiva interacionista bakhtiniana que funda a linguagem e, portanto, o texto que materializa seu uso como uma relação dialógica compreendida entre infinitos diálogos anteriores e posteriores e que por isso pode ser eternamente re-lido e re-significado, a partir do momento histórico e das posições axiológicas dos sujeitos sociais que a ele têm acesso.

\title{
NOTAS
}

1 Doutoranda em Linguística pela Universidade Federal de Santa Catarina (Florianópolis, SC), professora da Universidade Federal do Amazonas (Humaitá, AM) e bolsista da Fundação de Amparo à Pesquisa do Estado do Amazonas (FAPEAM).

\section{THE INTERACTIONIST APPROACH OF MULTIMODALITY TEXTUAL AND TEACHING CRITICAL READING}

\begin{abstract}
Given the emergence of new literacies, especially with regard to the aspect of multimodal texts belonging to genres recurrent in public spheres, whereby interact different social subjects of the current globalized world, impose ourselves the urgent task of reflecting on the status of the text in the social practices of contemporary life and to reconsider the processes of teaching and learning of reading they undergo the
\end{abstract}


students - subjects in training, potential critical readers. This time, we aimed in this paper is present to the reading of a text belonging to the genus multimodal magazine cover under assuming the reading as should be done at school. Therefore, the prospects are based on the interactional language and critical reading, respectively subsidized in Bakhtin and Freire and somehow both contemplated in the ideals underlying the Parâmetro Curricular Nacional de Língua Portuguesa. We emphasize here that reading made is more suitable for the high school segment, depending on the topic and knowledge collected for his apprehension, not intending, however, serve as a model or methodological proposal, which would go against the perspectives that guided this work.

Keywords: Multimodality. Social interactionist perspective. Critical reading. Education.

\section{REFERÊNCIAS}

BAKHTIN, Mikhail. Estética da criação verbal. 4. ed. São Paulo: Martins Fontes, 2003.

. Marxismo e filosofia da linguagem: problemas fundamentais do método sociológico na ciência da linguagem. 4. ed. São Paulo: Hucitec, 1988.

BENTES, A. C.; RAMOS, P.; ALVES FILHO, F.. Enfrentando desafios no campo dos estudos do texto. In: BENTES, A. Christina; LEITE, Marli Quadros (Orgs.).

Linguística de texto e análise da conversação: panorama das pesquisas no Brasil. São Paulo: Cortez, 2010.

BRASIL. Secretaria de Educação Fundamental. Parâmetros curriculares nacionais: terceiro e quarto ciclos do ensino fundamental: língua portuguesa. Brasília:

MEC/SEF, 1998.

BRITTO, Luiz Percival Leme. O ensino da leitura e da escrita numa perspectiva transdisciplinar. In: CORREA, D. A.; SALEH, P. B. de O. (Org.) Práticas de letramento no ensino: leitura, escrita e discurso. São Paulo: Parábola Editorial; Ponta Grossa, PR: UEPG, 2007.

FREIRE, Paulo. A importância do ato de ler: em três artigos que se completam. São Paulo: Cortez, 1982.

KOCH, Ingedore Villaça; TRAVAGLIA, Luiz Carlos. A coerência textual. 11.ed. São Paulo: Contexto, 2001.

SILVEIRA, A. P. K. da; ROHLING, N.; RODRIGUES, R. H. A análise dialógica dos gêneros do discurso e os estudos do letramento: glossário para iniciantes.

Florianópolis: DIOESC, 2012. 
VEJA. 2008. São Paulo: Abril, n. 33, ago. 2008, edição 2074, ano 41, p. 140. Capa. Disponível em: <http://veja.abril.com.br/acervodigital/home.aspx>. Acesso em: 02 dez. 2012. 